\section{VYUŽITÍ POČÍTAČOVÝCH 3D MODELŮ ANATOMIE ČLOVĚKA}

\section{Tomáš Kulhánek, Martin Brož, Jiří Kofránek}

\section{Abstrakt}

Počítačové 3D modely anatomie člověka jsou podkladem řady výukových materiálů a aplikací. Příspěvek uvede príklad konstrukce realistického 3D modelu vybraných částí anatomie z volně dostupných dat získaných z databáze BodyParts3D. Tato data opatřena texturou a prípadně upravena slouží jako podklad pro webovou aplikaci projektu "Simulátor Virtuálního Pacienta", který v anatomickém kontextu slouží pro výuku vybraných fyziologických regulací.

\section{Aplikace 3D anatomie člověka}

Počítačové 3D modely anatomie se stávají čím dál více součástí výukových aplikací na lékařských fakultách a mohou být použity pro rozšiření výuky anatomie a medicíny obecně at’ už ve trídě nebo samostudiem.

V rámci projektu BioDigital Human [1][2] tým na New York University s firmou BioDigital Systems vytvořil detailní 3D modely anatomie člověka. Data 3D modelů jsou vloženy do 3D platformy webové aplikace, která umožňuje vizualizaci za pomocí prohližeče bez nutnosti instalace pluginů třetích stran jen pomocí nového standardu WebGL. Základní prístup do této aplikace je zdarma. Platforma navíc poskytuje programové API rozhraní pro integraci vlastních webových aplikací s 3D vizualizací.
Projekt GoogleBody vytvořil obdobný produkt, 3D lidské anatomie zobrazitelné v prohlížeči bez nutnosti instalace pluginů nebo jiných prohlížečů třetích stran jen pomocí standardu WebGL[3], dnes dostupný jako komerční produkt ZygoteBody [4][5] v základní verzi dostupné zdarma. Kromě jiného aplikace nabízí placenou verzi datasetu 3D modelů k využití pro další účely vývoje, vizualizace apod.

Srovnatelná aplikace Complete Anatomy [6], Visual Body a další vyžadují instalaci specifické aplikace, která kromě 3D modelů obsahuje proprietární vizualizační software.Placená verze je detailnější.

\section{Databáze 3D objektů}

3D modely které webové aplikace zobrazují se získávají kombinací různých technik, at' už medicínských zobrazovacích metod, jako magnetické rezonance, počítačové tomografie, aj. až po čistě grafické, umělecké práce počítačových grafiků. V rámci projektu Visible Human Project [13] byly naskenovány snímky tenkých řezů těl zemřelých dárců a tyto snímky byly zdigitalizovány a jsou volně dostupné [14]. V rámci projektu BodyParts3D[15] se skenovalo živé tělo metodou magnetické rezonance a postupně se segmentovalo a opatřilo anotacemi podle ontologie Foundational Model of Anatomy (FMA)[16]. Na Obr 1. a Obr 2. je naznačen postup jak získat požadovaný 3D model tkáně a exportovat ve formátu OBJ.

Obecná platforma Sketchfab[11] nabízí databázi 3D objektů z různých oborů a krom objektů nabízí programové api a služby pro integraci 3D vizualizace do vlastní prezentace. Tato platforma se používá např. v oblasti kulturního dědictví, muzea a různé galerie zde publikují naskenované 3D artefakty, sdílejí

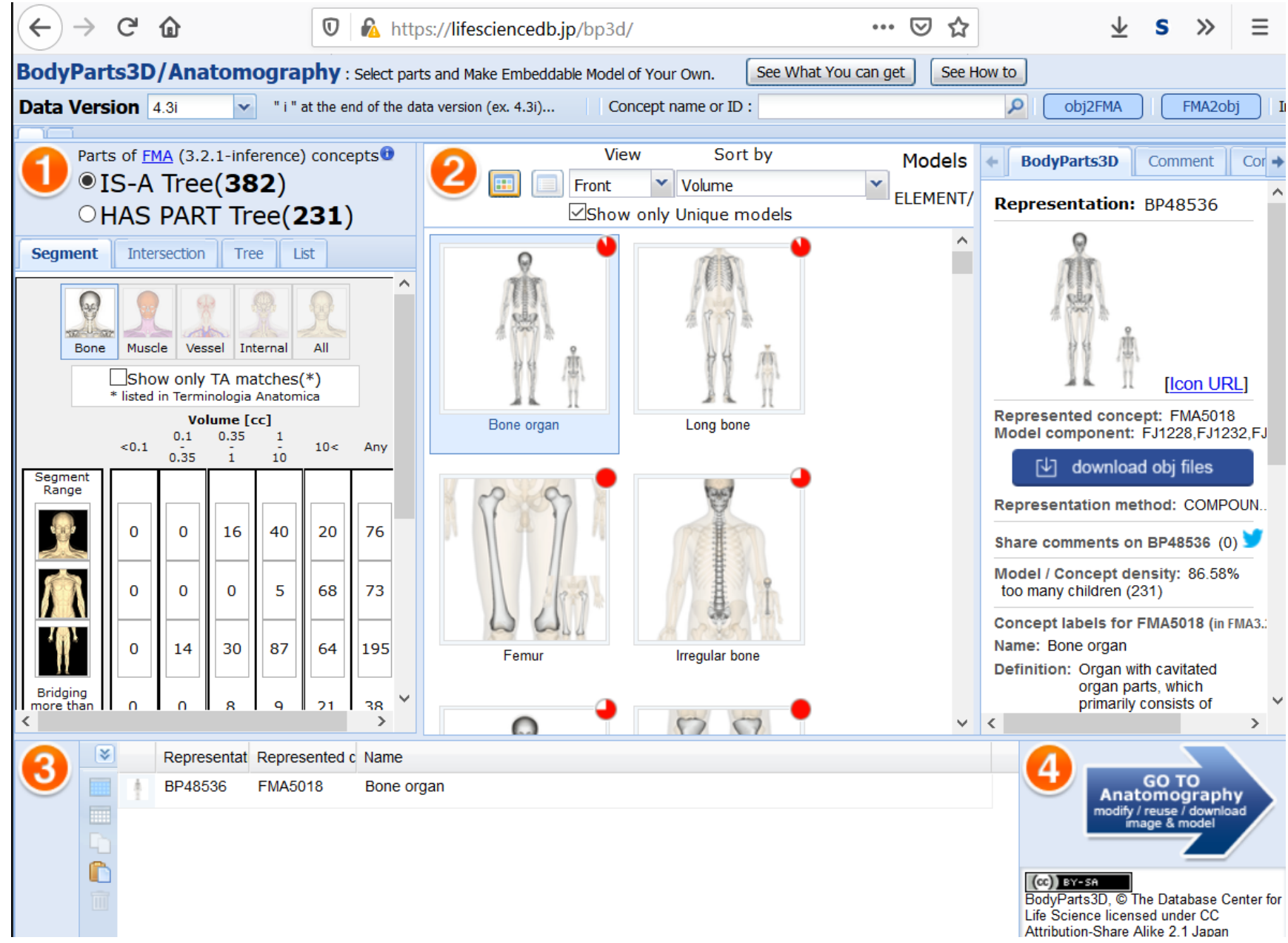

Obrázek 1 - Ve webové aplikaci BodyParts3D/Anatomography Ize vybrat několik částí podle typu tkání a podle segmentu v těle (1). V části (2) vybrán dataset s kompletní kostrou. Do části (3) Ize přidávat dalši segmenty. (4) Ize prohližet vybrané datasety viz Obr. 2. 


\begin{tabular}{|c|c|c|}
\hline$\rightarrow$ C $\mathrm{C}$ & (1) https://lifesciencedb.jp/bp3d/ & ... 田 \\
\hline
\end{tabular}

BodyParts3D/Anatomography : Select parts and Make Embeddable Model of Your Own. See What You can get See How to

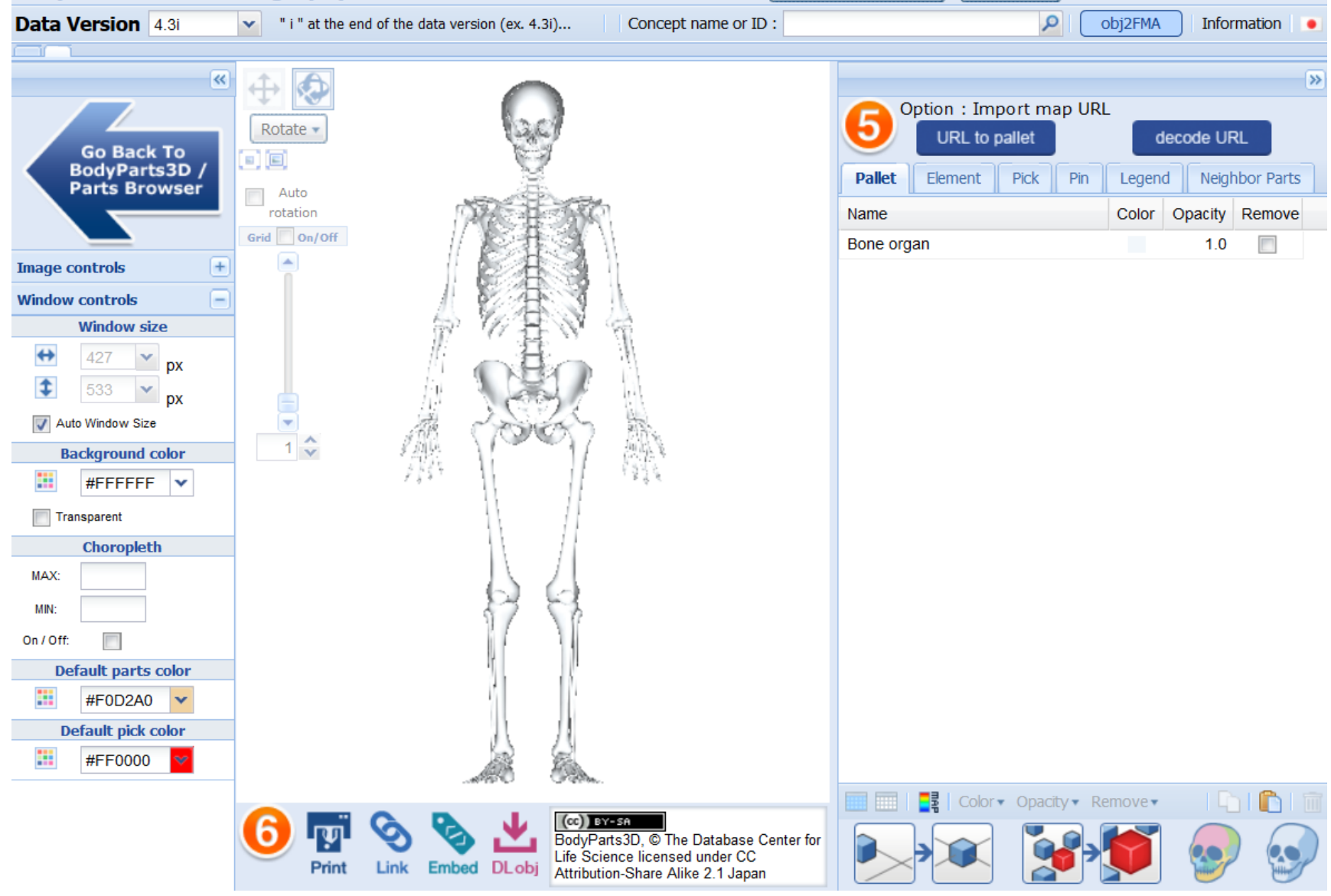

Obrázek 2 - Možný způsob Exportu jako archiv ZIP s 3D objekty ve formátu OBJ

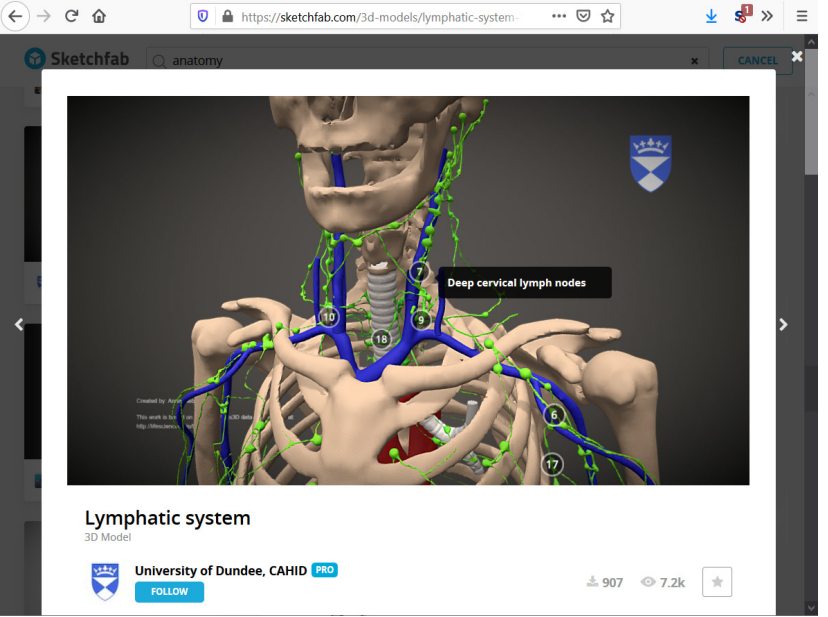

Obrázek 3 - Ukázka modelu kostry s lymfatickými systémy a interaktivními anotacemi dostupné ve webovém repozitári Sketchfab[11]. Jako podklad tohoto modelu byla použita data z repozitáře BodyParts3D[15].

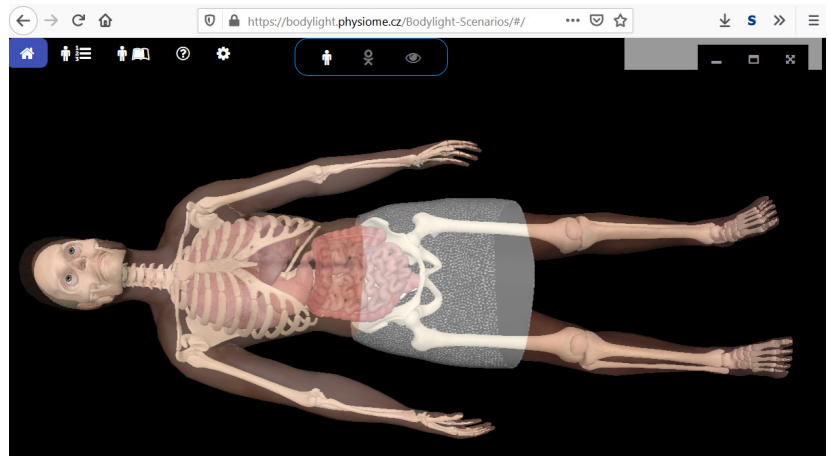

Obrázek 4 - Simulátor virtuálního pacienta [23], data 3D modelu získána $z$ BodyParts3D, textury upraveny ručně a exportováno do formátu GLTF. Navigační a vizualizační kontrolky dovolí zprůhlednit kǔži a kostru. Pomocí knihovny Three.js je 3D model interaktivní v běžném internetovém prohližeči. 
a obohacují své prezentace o 3D vizualizace a digitální anotace $v$ nich[12]. Na této platformě jsou rovněž dostupné medicínské artefakty, včetně anatomických struktur, bud' volně k použití, prípadně za poplatek. Na Obr 3. je ukázka lymfatického systému $\mathrm{s}$ anotacemi, který je rovněž $\mathrm{k}$ dispozici ke stažení ve formátu OBJ nebo GLTF.

\section{Vizualizace 3D modelů}

Z technologického hlediska, Ize aplikace pro vizualizaci anatomie člověka a podpory výuky medicínské anatomie a souvisejících předmětů oddělit ty, které k vizualizaci využívají již dnes dostupné standardy a mohou být prohliženy v standardním webovém prohlížeči. K 3D vizualizaci se prosadil od roku 2011 standard WebGL podporovaný současnými prohlížeči. Jde o Javascriptové $A P I$, které Ize použít pro vykreslování interaktivní grafiky v 2D a 3D. Protože WebGL API je nízkoúrovňové, existuje celá řada knihoven usnadňující vykreslování grafiky jako A-Frame[7], Babylon.js[8], PlayCanvas[9], Three.js[10], CopperLicht[6], aj.

\section{Výsledky}

Pro účely projektu "Virtuální pacient" byli vybrány data kostry a vnitřních orgánů z repozitáře BodyParts3D[15], některé orgány z repozitáře Sketchfab[11]. Tato hrubá data obsahují jen základní barvy materiálů, pro vytvoření realistické textury kůže, kostry a povrchu tkání byl použit software Zbrush[18][19], Cinema4D[20] a plugin GLTF exporter [21]. Během tohoto zpracování byla vytvořena nová topologie, povrchy rozřezány pro tzv. UV mapping, tj. aby textura $v 2 D$ se správně namapovala na 3D povrch a upraveny povrchy pro realistické mapování textur.

Pro výměnu $3 \mathrm{D}$ dat mezi různými aplikacemi byly použity formáty OBJ a GLTF [17]. Export výsledků z aplikací Zbrush a Cinema4D byl opět ve formátu GLTF nebo OBJ. K závěrečným úpravám dat byl ještě použit webový nástroj Three.js editor, v kterém se upravila konečná podoba zobrazení ve webové aplikaci.

V knihovně Three.js byl realizováno nahrání dat ve formátu GLTF, které jsou nasvícené ve scéně předním a zadním světlem,natočen o $90^{\circ}$ do horizontální polohy v tmavém pozadí, viz Obr. 4.

Vznikající aplikace simulátoru virtuálního pacienta [23] dává do kontextu anatomické struktury s výkladem fyziologie a patofyziologie vybraných stavů, ve spojení s nástroji Bodylight Simulation Toolchain[21] pak takto vznikající aplikace mohou být podkladem pro výuku ve virtuální, či rozširrené realitě, kde 3D projekce dává kontextovou informaci pro složitý výklad. S pomocí výše dostupných repozitárư volně dostupných dat Ize vytvořit dobře vypadající 3D aplikaci zobrazující anatomii člověka. Největší přidaná hodnota takovýchto aplikací je doplnění textur a digitálních anotací na míru.

\section{Reference}

[1.] Qualter, J., Sculli, F., Oliker, A., Napier, Z., Lee, S., Garcia, J., ... Triola, M. (2012). The biodigital human: a web-based 3D platform for medical visualization and education. Studies In Health Technology And Informatics, 173, 359-361. https://doi.org/10.3233/978-1-61499$\underline{022-2-359}$

[2.] https://human.biodigital.com, Web, accessed March 2020

[3.] Blume, A., Chun, W., Kogan, D., Kokkevis, V., Weber, N., Petterson, R. W., \& Zeiger, R. (2011). Google Body: 3D Human Anatomy in the Browser. In ACM SIGGRAPH 2011 Talks. New York, NY, USA: Association for Computing Machinery. https://doi.org/10.1145/2037826.2037852

[4.] https://www.zygotebody.com Web, accessed March 2020

[5.] https://opensource.googleblog.com/2012/01/google-body-becomes-zygote-body-built.html, Web, accessed March 2020
[6.] CopperLicht, https://www.ambiera.com/copperlicht/index.htm/

[7.] A-Frame, https://aframe.io/

[8.] Babylon JS, https://www.babylonjs.com/

[9.] PlayCanvas, https://playcanvas.com/

[10.] Three.js, https://threejs.org/

[11.] SketchFab, https://www.sketchfab.com

[12.] Lloyd, J. (2016). Contextualizing 3D Cultural Heritage. In M. loannides, E. Fink, A. Moropoulou, M. Hagedorn-Saupe, A. Fresa, G. Liestøl, ... P. Grussenmeyer (Eds.), Digital Heritage. Progress in Cultural Heritage: Documentation, Preservation, and Protection (pp. 859-868). Cham: Springer International Publishing. https://doi. org/10.1007/978-3-319-48496-9_69

[13.] Ackerman, M. J. (1998). The Visible Human Project. Proceedings of the IEEE, 86(3), 504-511. https://doi.org/10.1109/5.662875

[14.] Visible Human Project: https://www.n/m.nih.gov/research/visible/ visible human.html, accessed March 2020

[15.] Mitsuhashi, N., Fujieda, K., Tamura, T., Kawamoto, S., Takagi, T., \& Okubo, K. (2008). BodyParts3D: 3D structure database for anatomical concepts. Nucleic Acids Research, 37(suppl_1), D782-D785. https://doi.org/10.1093/nar/gkn613

[16.] FMA http://si.washington.edu/projects/fma, accessed March 2020

[17.] GLTF https://www.khronos.org/gltf/

[18.] Spencer, S. (2010). Zbrush digital sculpting human Anatomy. John Wiley \& Sons.

[19.] Zbrush, https://pixologic.com/ Web accessed March 2020

[20.] Cinema4D, https://www.maxon.net/en-us/products/cinema-4d/ overview/, Web, accessed March 2020

[21.] Šilar, J., Polák, D., Mládek, A., Ježek, F., Kurtz, T. W., DiCarlo, S. E., ... Kofranek, J. (2019). Development of In-Browser Simulators for Medical Education: Introduction of a Novel Software Toolchain. Journal of Medical Internet Research, 21(7), e14160. https://doi. org/10.2196/14160

[22.] Three.js editor, https://threejs.org/editor

[23.] Simulátor virtuálního pacienta, https://bodylight.physiome.cz/ Bodylight-Scenarios/

\section{Kontakt}

Mgr. Tomáš Kulhánek, Ph.D.

Oddělení biokybernetiky Ústav patologické fyiologie 1. LF UK email: tomas.kulhanek@matfyz.cz tel: +420775178931 